\title{
Long Chain Polyunsaturated Fatty Acids (LCPUFAs) in the Prevention of Food Allergy
}

\author{
Tamara Hoppenbrouwers ${ }^{1}$, Jelena H. Cvejić Hogervorst ${ }^{2}$, Johan Garssen ${ }^{3,4}$, \\ Harry J. Wichers ${ }^{5}$ and Linette E. M. Willemsen ${ }^{4 *}$ \\ ${ }^{1}$ Food Quality and Design, Wageningen University \& Research, Wageningen, Netherlands, ${ }^{2}$ Department of Pharmacy, \\ Faculty of Medicine, University of Novi Sad, Novi Sad, Serbia, ${ }^{3}$ Department of Immunology, Nutricia Research BV, Utrecht, \\ Netherlands, ${ }^{4}$ Division of Pharmacology, Department of Pharmaceutical Sciences, Faculty of Science, Utrecht University, \\ Utrecht, Netherlands, ${ }^{5}$ Food \& Biobased Research, Wageningen University \& Research, Wageningen, Netherlands
}

N-3 long chain polyunsaturated fatty acids (LCPUFAs) are considered to possess protective properties for human health by impacting on immunological reactions. An "inflammation-suppressive" effect appears to be the common denominator of the beneficial effects of most of these dietary components which may protect against the development of chronic immune disorders such as (food) allergy. LCPUFAs, especially n-3 LCPUFAs, have been shown to interact with both the sensitization as well as the effector phase in food allergy in pre-clinical models. In this review, we explore the anti-allergic properties of LCPUFAs by providing an overview of clinical, in vivo and in vitro studies. Furthermore, we discuss the susceptibility of LCPUFAs to lipid oxidation and possible strategies to support the efficacy of LCPUFAs in reducing the allergy risk by using additional components with anti-oxidative and anti-inflammatory capacities such as the flavonoid quercetin. Finally, we propose new strategies to prevent (food) allergy using combinations of LCPUFAs and additional nutrients in diets or supplements, and postulate to investigate the use of LCPUFAs in allergic symptom relief.

Keywords: food allergy, PUFA, LCPUFA, immune response, anti-inflammatory

\section{INTRODUCTION}

Allergic reactions, particularly as a result of food allergy, can be life-threatening. The frequency of reported allergies and the severity of allergies in the Western world has increased significantly, and is forecasted to affect e.g., $50 \%$ of the EU's population by 2025 (1). Food allergy is one of the first allergies to arise early in life and has an overall worldwide increasing prevalence of $5-10 \%$, highly dependent on the country $(2,3)$. The majority of these allergies are triggered by milk, eggs, peanuts, other nuts, wheat, soy, and (shell)fish. Of these, reactions to milk, eggs, and peanuts are the most prevalent in children, while peanuts and (shell)fish are the major triggers of allergic reactions in teenagers and adults (4).

The majority of food allergy is known as a type I allergy, indicating that it is mediated by a relatively acute response in which immunoglobulin $\mathrm{E}$ (IgE) is the pivotal antibody involved. However, also in the absence of allergen specific IgE, acute allergic responses may occur upon ingestion of the culprit food allergens. The immunological mechanisms behind food allergy have been extensively explained previously (5). Briefly, food allergy can be subdivided into two phases: allergic sensitization and the allergic effector response. 


\section{Allergic Sensitization}

Allergenic proteins in foods, are taken up by antigen-presenting cells (APCs), and of these, dendritic cells (DCs) are mainly involved in the presentation of antigens to naive T-cells. This normally results in tolerance toward harmless food proteins. However, Th2 polarized immunity and mixed Th2 and Th1 driven allergen specific immune responses occur in the acute and chronic phase in allergy, respectively. In order to activate T-cells, two signals are needed: the binding of the T-cell receptor (TCR) specifically recognizing the allergenic epitopes presented via MHCII by DCs, and interaction of the co-stimulatory molecules CD28, CTLA-1/4 and LFA-1, and CD134 on the T-cell with, respectively, B-7 (CD80/CD86) and ICAM-1 and OX40L on the DC (6). Differentiation into CD4+ T-cells, or T-helper (Th) cells Th1, Th2, and Treg is regulated by many different factors, e.g., cytokines and/or chemokines such as IL-12 and IFN $\gamma$ (Th1), IL4, CCL17, and CCL22 (Th2) and IL-10 (Treg) and co-stimulatory molecules such as LFA-1/ICAM-1 (Th1) and CD134 and OX40L (Th2) (7). In allergy, OX40L expression by DCs has been reported to be the most important Th2 driving factor (8). Th2 cell delivered IL-4 plays a key role in development of type 1 allergy by driving $\operatorname{IgE}$ secretion via induction of allergen specific $\operatorname{IgE}$ isotype switching in B-cells and antibody production by plasma cells, resulting in allergic sensitization $(9,10)$. Beyond binding to the FceRI of allergic effector cells such as mast cells and basophils, IgE can also bind to this receptor on DCs, further stimulating the immune response. Finally, Th1 cell derived mediators (IFN $\gamma$ ) downregulate Th2 cell proliferation and Treg cells are able to downregulate the proliferation and activation of both Th1 and Th2 cells.

\section{Allergic Effector Response}

Upon a second encounter with the allergen, crosslinking of the IgE bound FceR1 receptor by the allergen results in mast cell and basophil activation and degranulation and the induction of the allergic effector response. Mast cells release many different components such as histamine, proteases, heparin, leukotrienes, prostaglandins, cytokines, and chemokines, which are all involved in the generation of the allergic symptoms by causing redness, swelling, and vasodilation. Sometimes this may even lead to an anaphylactic highly acute reaction within minutes.

\section{Dietary and Environmental Determinants of Food Allergy Risk}

The development of the gastro-intestinal and systemic immune system is in part driven by the intestinal microbiome. Microbiome disturbances have been reported to be associated with different types of allergies (11). Changes in (children's) microbiome are claimed to be important in the increase in food allergy cases although it is not completely evident what is cause or consequence (12). Such microbiome changes can be caused by, among others, an increased intake of fat and processed food, reduced intake of dietary fibers, fruits and vegetables, and the use of antibiotics during pregnancy and/or in early life (12-14). Currently no standard treatment is available for food allergy, therefore, the need for prevention and resolving allergy is becoming of major concern. One of the factors that may contribute to the risk of developing food allergy is the quantity and quality of fat used in current diets. The typical Western diet is rich in n-6 polyunsaturated fatty acids (PUFAs) and poor in n-3 PUFAs. The ideal balance of n-3:n-6 PUFAs has been established to be between 1:3 and 1:5. However, in the current Western diet, the balance has been shifted to $1: 10$ to $1: 30$, which is dramatically out of balance at the expense of the n-3 PUFAs. This shift can affect both the microbiome (15) and the immune system (16) of unborn children when the mother consumes food rich in n-6 PUFA. It has been recognized that nutrition plays an important role in the development, maintenance, and appropriate functioning of the immune system, and consequently it may also contribute to the prevention and management of for example food allergies. Food constituents, such as longchain polyunsaturated fatty acids (LCPUFAs) may be able to influence the allergic sensitization and/or effector response through multiple biological pathways. In this review we will explore the current knowledge on the use of LCPUFAs in the prevention of food allergy, and aim to provide insights to improve future outcomes.

\section{LONG-CHAIN POLYUNSATURATED FATTY ACIDS}

PUFAs are a group of acids that contain more than one double bond in their molecular structure. The most important PUFA groups are omega-3 (n-3) and omega-6 (n-6), depending on the placement of the first double bond, which is either at the third or the sixth carbon of the methyl end (Figure 1). In the n-3 group, essential $\alpha$-linolenic acid (ALA, 18:3n-3) is enzymatically converted into stearidonic acid (SDA), and elongated into long-chain eicosapentaenoic acid (EPA, 20:5n3 ), which is converted into docosapentaenoic acid (DPA, 22:5n3 ) and then docosahexaenoic acid (DHA, 22:6n-3). In the n-6 group, essential linoleic acid (LA, 18:2n-6) is converted into longchain arachidonic acid (AA, 20:4n-6) (Figure 1). However, the conversion rate to LCPUFA is limited, and n-3 PUFA compete with n-6 PUFA for conversion since the same elongation and desaturation enzymes are used. The n-3 LCPUFA can be obtained from fatty fish, such as salmon, tuna, mackerel, herring and sardines, and fish oil. More sustainable sources such as vegetable oil, nuts, and seeds contain n-3 PUFA ALA, while algae oil is rich in n-3 LCPUFAs DHA and EPA.

As the result of dietary changes over the last decades, the balance between n-3 and n-6 PUFAs has been disturbed in favor of n-6. N-6 PUFAs, present in vegetable oils, such as sunflower, soybean, and corn oil, are increasingly consumed, while the intake of n-3 LCPUFA, at least in westernized countries, is generally low. Since n-6 LCPUFA AA is associated with proinflammatory and n-3 LCPUFAs EPA and DHA with antiinflammatory activities, the mentioned imbalance is possibly contributing to the rise of non-communicable diseases, including allergies. Usually recommended consumption of two portions of fatty fish per week corresponds to $200 \mathrm{mg}$ DHA per day (17). Due to efficient digestion and absorption, approximately more than 


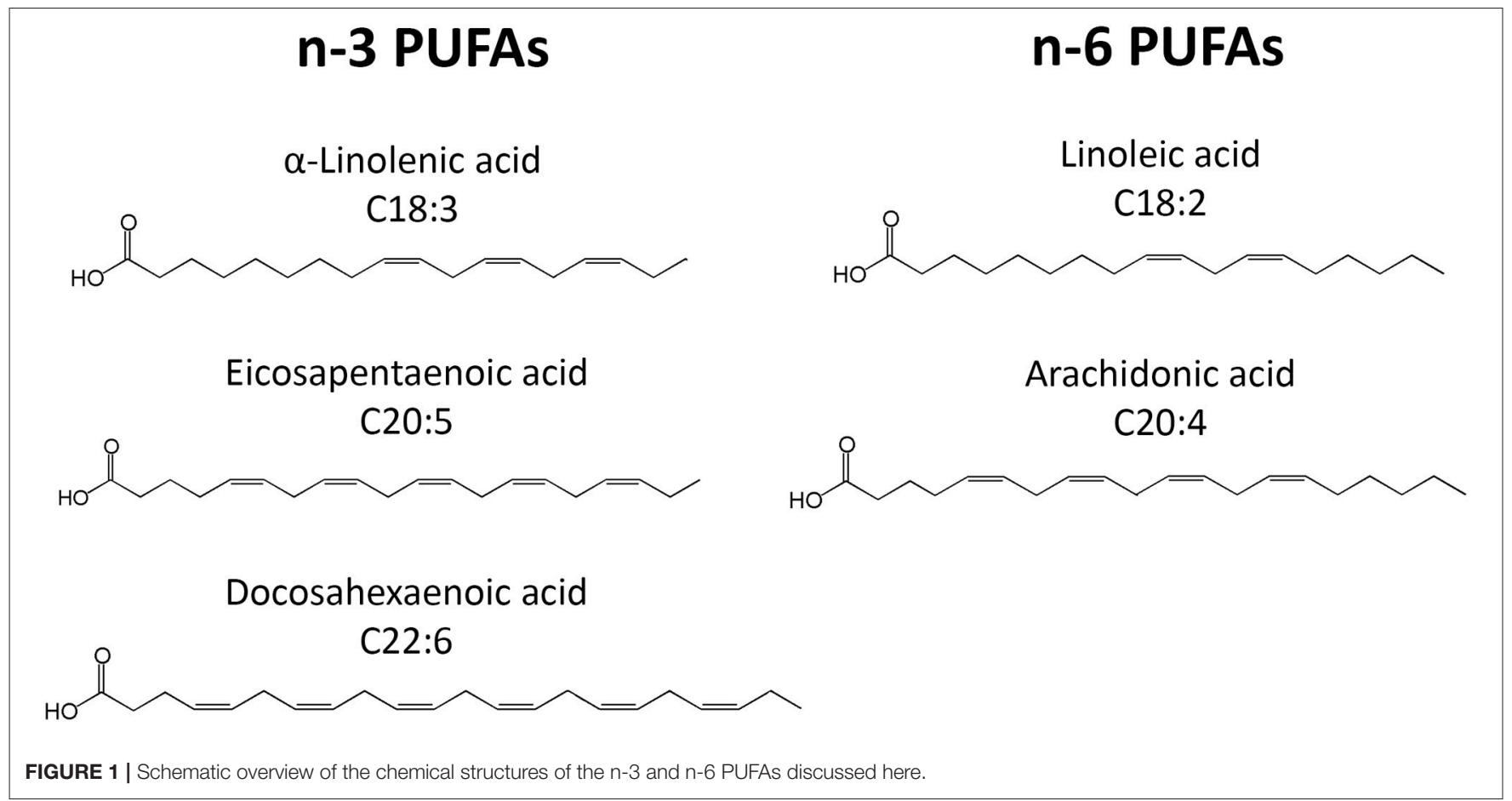

95\% of ingested fatty acids become biologically available and get incorporated in the phospholipid bilayer of cell membranes (18).

\section{IMMUNOMODULATION BY PUFAS IN FOOD ALLERGY}

PUFAs have attracted attention for prevention of food allergy for many years, mainly because they are able to target nearly every cell type within both the allergic sensitization and effector phase (Figure 2). Upon ingestion, PUFAs are incorporated into the cell membrane, thereby influencing cell properties such as membrane fluidity and the inflammatory response (19). In in vitro experiments, PUFAs are usually added in concentrations ranging from 2 to $100 \mu \mathrm{M}(20-23)$ to study the effect on mast cells, DCs, T-cells, or a combination of the latter two. Despite this variation, most studies report similar results.

During the sensitization phase, PUFAs are able to intervene in pathways of DCs, T-cells, and IgE production by B-cells as shown in pre-clinical models. In mouse myeloid DCs activated with LPS in vitro, DHA has been shown to inhibit MHC-II expression, activation of CD86 through TLR4, expression of co-stimulatory molecules (CD40, CD80, and CD86) and inflammatory cytokine production (IL-6 and IL-12p70), therefore also inhibiting T-cell activation (24). This has also been shown in vitro using human DCs (25). Furthermore, in vivo, fish oils rich in the n-3 LCPUFAs DHA and EPA have been found to modulate the function of Tcells by suppressing signal transduction through the TCR and CD28, thereby reducing activation by DCs and proliferation of $\mathrm{CD}^{+}{ }^{+}$T-cells (26). Proliferation of $\mathrm{CD} 4^{+} \mathrm{T}$-cells has also been described to be reduced directly by incorporation of EPA, DHA and AA in the membrane in both ex vivo and in vitro studies (27, 28). Downregulation of DC-T-cell activation results in a decrease in secretion of pro-inflammatory cytokines TNF- $\alpha$ and IL-12 and an increase in IL-10 production and expression $(22,25,29)$. N-3 LCPUFAs DHA and EPA have been described to also modulate inflammation by binding to several receptors, such as GPR120 and nuclear receptor PPAR $\alpha / \gamma$ (30). Furthermore, DHA and, to a lesser extent, EPA, have been reported to prevent and reduce cow's milk and peanut allergy in mice (31) by reducing IgE, IgG1, and IgG2a levels and the generation of Treg, while lowering both Th2 and Th1 activation (32). In contrast, a 10\% soybean diet, rich in-6 PUFAs, has been reported to enhance the allergic reaction to cow's milk by enhancing Th2 cell polarization and the allergic effector response (33). This could be reduced by increasing the amount of $n-3$ LCPUFAs in the diet, indicating that the ratio of n-3:n-6 PUFAs in the diet is important in immune system modulation (31). Therefore, unraveling the differential effects of n-3 vs. n-6 LCPUFAs or mixtures on immune cells may reveal new avenues for more specific nutritional interventions.

In the effector phase, PUFAs (n-3 alone or in varying ratios to $\mathrm{n}-6)$ have been shown to reduce histamine and leukotriene B4 levels when supplemented to mast cells (MCs) $(34,35)$. However, n-6 PUFA AA has been shown to activate intracellular ROS production, increase $\mathrm{MC}$ degranulation mediated by IgE, and TNF- $\alpha$ and $\mathrm{PGD}_{2}$ release $(36,37)$. AA is an eicosanoid precursor and can be converted via the cyclooxygenase pathway into prostaglandin $\mathrm{H} 2\left(\mathrm{PGH}_{2}\right)$. Both $\mathrm{PGD}_{2}$ and $\mathrm{PGE}_{2}$ are synthesized from $\mathrm{PGH}_{2}$, which are important in allergic symptoms by increasing vascular permeability and in maintaining allergy through the activation of Th2 cells. $\mathrm{PGD}_{2}$ is a prostaglandin, which is a subclass of eicosanoids, mainly secreted by MCs 


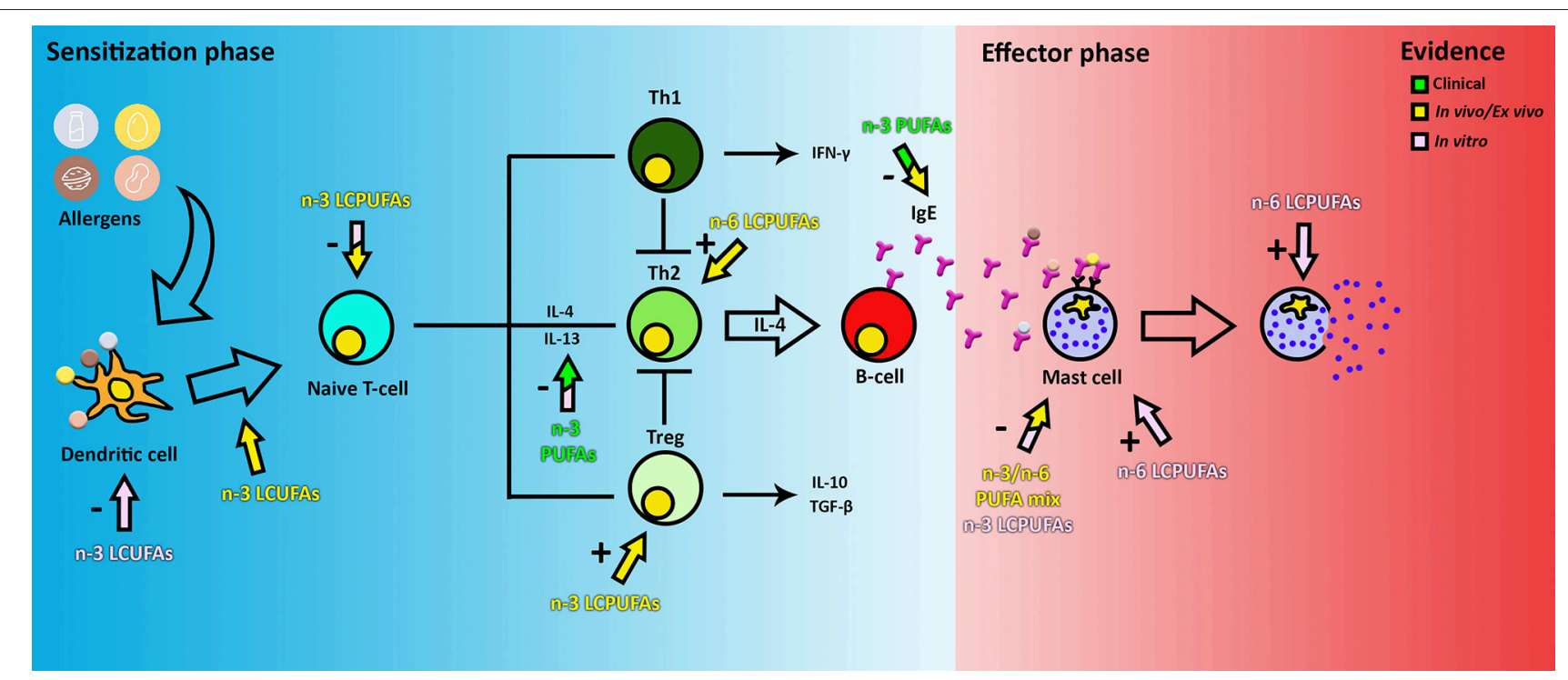

FIGURE 2 | The effect of PUFAs on food allergy. The color of the arrows and text indicate if the evidence is obtained from clinical, in vivo or in vitro data. The + or-indicates if the observed effect is an inhibitory or stimulatory response of a certain cell type. Note that clinical and in vivo arrows indicate the observed end stage effects only, this may not be a reflection of the direct effect of PUFAs on the target cells. Therefore, the components could actually target a cell group earlier in the pathway.

and one of the key molecules in the induction of food allergy symptoms (38). On the other hand, n-3 PUFAs DHA and EPA inhibit MC degranulation, and IL-4 and IL13 secretion and $\mathrm{PGD}_{2}$ release by $\mathrm{MCs}$ (37). DHA, which like EPA, is known to compete with AA for membrane incorporation, has been shown to be negatively correlated to the AA metabolite $\mathrm{PGE}_{2}$ levels in human serum (39), supporting the findings that n-3 LCPUFA DHA is potentially effective in decreasing food allergy risk and symptoms in the effector phase.

Clinical trials exploring the effect of n-3 LCPUFAs during pregnancy and/or lactation on allergic outcomes (e.g., food allergy, asthma, atopy, and wheezing) are contradicting. Supplementation of fish oil starting early during pregnancy and continuing during breastfeeding was shown to reduce allergic sensitization for food proteins in the offspring (40). Lower Th2 associated cytokine levels of IL-13 were measured in the plasma of these children (41). Formula supplemented with AA and DHA was also shown to prevent allergy development in young children compared to non-supplemented formula milk (42). From epidemiological studies it is known that allergy is associated with low n-3 LCPUFAs, especially EPA and DHA, and high n-6 LCPUFAs in plasma or serum $(43,44)$, indicating a protective effect of $n-3$ LCPUFAs and the importance of aiming for an optimal balance of n-3 over n-6 LCPUFA (1:3-1:5) for immune development in neonates. However, follow up studies, often using the age group 1-5 years, report no lasting effects on sensitization prevention when n-3 LCPUFAs were supplemented during gestation (45-47). By contrast, in another study 2 years after supplementation, lower IgE levels in children whose mothers received n-3 LCPUFAs were still detected (48). In an extensive Cochrane review on the supplementation of fatty fish or n-3 PUFAs during pregnancy combining the results of eight different trials, including 3,366 woman and 3,175 children, it was concluded that the evidence for effective food sensitization and allergy prevention however is limited (49). Although a reduction in IgE-mediated allergy was observed in children between 12 and 36 months old, and reduced sensitization to egg was reported, no significant differences have been found in sensitization to cow's milk, wheat and peanut proteins. Of note, most trials (5/8) supplemented the woman with n-3 LCPUFAs prenatally only $(45,50-53)$, two only shortly after delivery $(54,55)$, whilst only one trial supplemented both pre- and post-natal (40). The latter study however showed the biggest effect on prevention of sensitization and allergic outcome in the first year of life. Hence, the timing of intervention during gestation, continuation during lactation, the dose of n-3 LCPUFA oils supplemented, the achieved levels of n-3 LCPUFA membrane incorporation and genetic pre-disposition may be determinants for possible allergy protective capacities of $n-3$ LCPUFA in neonates. Continuation of n-3 LCPUFA supplementation during early life maybe implicated to enforce possible beneficial effects on allergic sensitization and atopic risk during infancy (56). A summary of all LCPUFA effects in clinical, in/ex vivo and in vitro described in this review are summarized in Table 1.

\section{COMBINING LCPUFAS TO PREVENT LIPID PEROXIDATION}

When using n-3 LCPUFAs as supplements aiming to reduce the risk of allergic sensitization in order to lower the chance of food allergy development, their high susceptibility to oxidative degradation should be carefully dealt with. Several strategies can 
TABLE 1 | A summary of all PUFA related experiments and clinical trials described in this review.

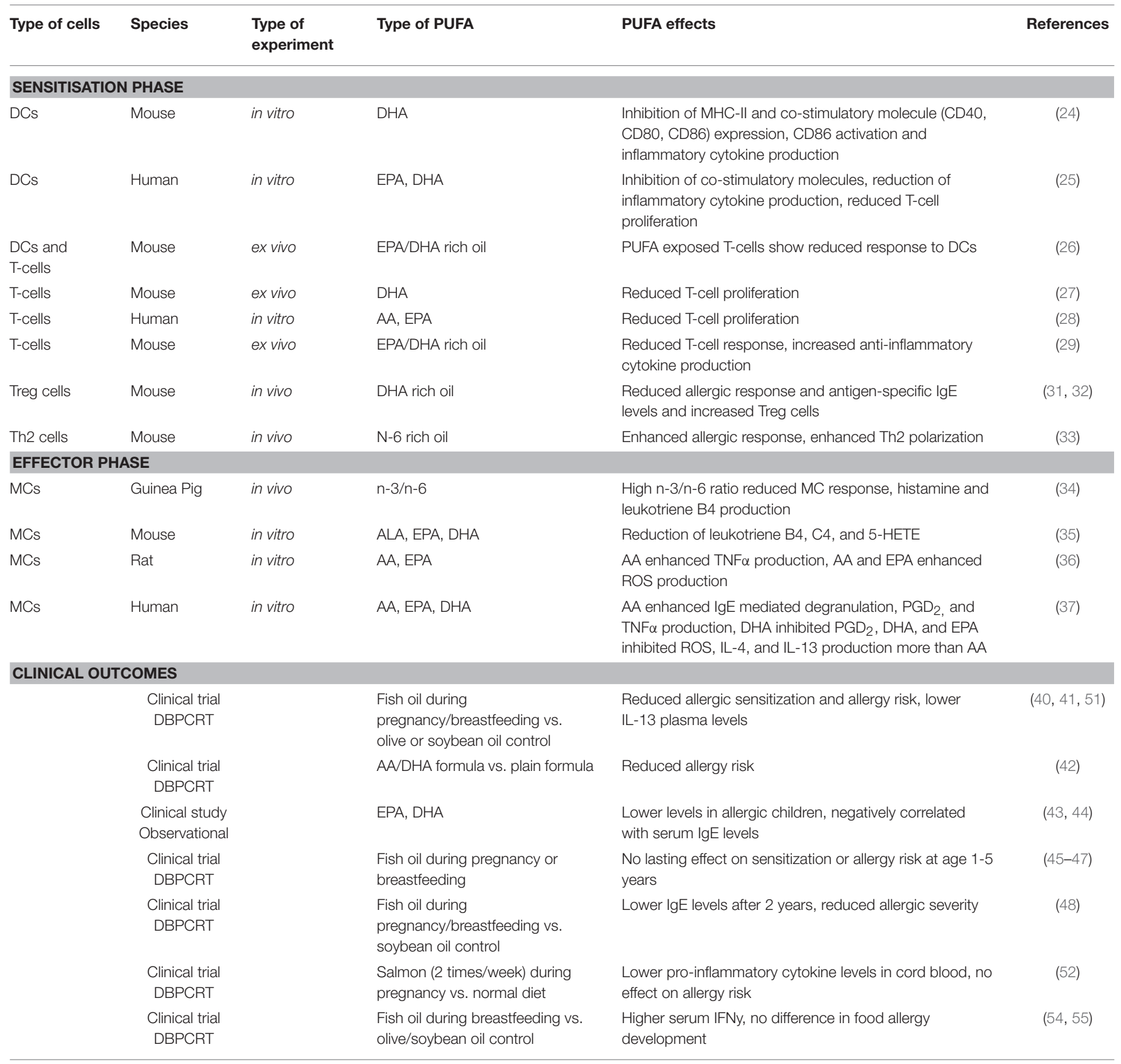

In all clinical trials the mother received fish oil during pregnancy and/or breastfeeding and effects were measured in the children. DBPCRT, double blind placebo controlled randomized trial.

be used to reduce lipid peroxidation of LCPUFAs. For example, Raederstorff et al. (57) stated that the intake of PUFAs should be directly linked to the vitamin E requirement. Vitamin E is a fat-soluble vitamin that has a principal role in defense against oxidant-induced membrane injury and it may have antiinflammatory capacities as well (58). As vitamin E resides in the membrane phospholipid bilayer in cells, as do PUFAs (59), it facilitates membrane stabilization and protection against lipid peroxidation by scavenging peroxyl fatty acid radicals that will then be transferred to liquid phase anti-oxidants like vitamin C.
Therefore, based on the amount of PUFAs in an average Western diet, the authors recommend a dose of vitamin E between 12 and $20 \mathrm{mg} /$ day (57).

Another possible group that can help to reduce lipid peroxidation are flavonoids. Flavonoids also have antiinflammatory effects beyond their anti-oxidant activity and can inhibit enzymes involved in the production of eicosanoids. Therefore, flavonoids have been proposed to be useful in allergy prevention (60-63). By interaction with ROS (superoxide $\mathrm{O}_{2}$, hydroxyl radical $\bullet \mathrm{OH}$ and $\mathrm{H}_{2} \mathrm{O}_{2}$ ) and RNS (Reactive Nitrogen 
Species), flavonoids can terminate the chain reaction in lipid peroxidation caused by free radical formation before cell viability is seriously affected and they are able to modulate inflammatory processes $(64,65)$. Importantly, ROS have been shown to enhance the differentiation to Th2 cells by stimulating the production of IL-4 through the activation of STAT6 and GATA3 in a mouse model (66). The most studied flavonoid might be quercetin and its metabolites have been shown to be localized in the phospholipid bilayer $(67,68)$. Quercetin can be found in red wine, apples, green tea and onion and contains both anti-inflammatory and anti-oxidative properties (69). It has been reported to inhibit leukotriene B4 levels in MCs (70), reduce the gene expression of pro-inflammatory cytokines (TNF- $\alpha$, IL-1 $\beta$, IL-6, and IL-8) (71) and suppress inflammation in IgE-mediated intestinal epithelial cell (Caco-2) and rat basophil (RBL-2H3) activation models (72). Flavonoids have also been shown to inhibit allergic effector cells such as MCs known to contribute to allergic symptoms (73). For example, inhalation of quercetin has been shown to lower MC numbers and allergy associated cytokine levels such as IL-4, in a mouse model for allergic inflammatory lung disease (74). Therefore, it may be considered to combine LCPUFAs supplementation for food allergy prevention with flavonoids like quercetin, for its anti-oxidant as well as anti-inflammatory properties which may contribute to the effects of n-3 LCPUFA in allergy prevention. In this regard, PUFA-flavonoid hybrids or conjugates or mixed flavonoid-fish oil supplements are at the moment explored by several groups albeit not yet as a purpose to reduce allergy risk (75-77).

\section{FUTURE PERSPECTIVES: PREVENTION AND TREATMENT OF FOOD ALLERGY}

Currently, in literature there are many discrepancies between studies regarding timing and dose of the n-3 LCPUFA supplementation, as well as the described outcomes. Therefore, as mentioned previously, one strategy to more extensively study allergy prevention could be a constant supplementation of n3 LCPUFAs to children, both during and after pregnancy (by breast feeding or formula), which will maintain adequate n-3 LCPUFA levels. Another, perhaps more interesting strategy for food allergy prevention may be to supplement pregnant women and their offspring with a combination of LCPUFAs, proper levels of vitamin $\mathrm{E}$ and flavonoids as additional component with anti-oxidant and anti-inflammatory properties. A balanced intake of LCPUFAs, vitamins, and flavonoids could be achieved

\section{REFERENCES}

1. EAACI. The European Academy of Allergy and Clinical Immunology. (2015). Available online at: http://www.eaaci.org/documents/EAACI_Advocacy_ Manifesto.pdf (accessed May 12, 2019).

2. Savage J, Johns CB. Food allergy: epidemiology and natural history. Immunol Allergy Clin North Am. (2015) 35:45-59. doi: 10.1016/j.iac.2014.09.004

3. Tang ML, Mullins RJ. Food allergy: is prevalence increasing? Intern Med J. (2017) 47:256-61. doi: 10.1111/imj.13362 by a simple change in diet. Mediterranean food is an example of food containing multiple bioactive dietary components and frequently proposed to be beneficial for human health, as it contains fatty fish and nuts (rich in n-3 PUFAs), olive oil (rich in oleic acids and anti-oxidants), fruits (rich in vitamins and flavonoids), and wine (rich in flavonoids) (78). Several studies have shown a positive correlation between the Mediterranean diet, consisting mainly of fish, fruits, vegetables, legumes, nuts, and cereals, during pregnancy and a reduction of allergic asthma and rhinitis (79-81). Another popular source of flavonoids and micronutrients is cocoa from the cacao tree. In vivo, it has been shown to have immunomodulatory properties, including suppression of IgE, TNF- $\alpha$, and IL-10 levels $(82,83)$. Finally, a popular food supplement in the early 1900s was cod liver oil which is still being used mostly in Northern Europe countries and North America. It contains both vitamin $\mathrm{A}$ and $\mathrm{D}$ and is a sustainable source of n-3 LCPUFAs. Even though the use of cod liver oil could still be beneficial, as shown in a study on rheumatoid arthritis (84), others suggest that, because vitamin $\mathrm{A}$ and $\mathrm{D}$ are nowadays supplemented in our food, the intake could actually be harmful and positively correlated to asthma (85).

A striking observation when exploring the possibilities of LCPUFAs in food allergy is that while n-3 LCPUFAs are able to target both the sensitization and effector phase, all clinical trials and most in vivo studies focus only on prevention of sensitization and food allergy. Hence, studying the effects of $n$ 3 LCPUFA supplementation either or not with additive selected nutrients having anti-oxidant and anti-inflammatory properties not only in the prevention but also for allergic symptom relief may be considered. Therefore, more studies should be conducted exploring the conditions by which n-3 LCPUFAs and other nutrients are able to reduce the risk to develop food allergy and possibly the severity of allergic symptoms.

\section{AUTHOR CONTRIBUTIONS}

All authors listed have made a substantial, direct and intellectual contribution to the work, and approved it for publication.

\section{FUNDING}

This transnational project is part of the ERA-Net SUSFOOD2 with funding provided by national/regional sources and cofunding by the European Union's Horizon 2020 research and innovation programme. 
6. Tai Y, Wang Q, Korner H, Zhang L, Wei W. Molecular mechanisms of T cells activation by dendritic cells in autoimmune diseases. Front Pharmacol. (2018) 9:642. doi: 10.3389/fphar.2018.00642

7. Rogers PR, Croft M. CD28, Ox-40, LFA-1, and CD4 modulation of Th1/Th2 differentiation is directly dependent on the dose of antigen. J Immunol. (2000) 164:2955-63. doi: 10.4049/jimmunol.164.6.2955

8. Chu DK, Mohammed-Ali Z, Jimenez-Saiz R, Walker TD, Goncharova S, LlopGuevara A, et al. T helper cell IL-4 drives intestinal Th2 priming to oral peanut antigen, under the control of OX40L and independent of innate-like lymphocytes. Mucosal Immunol. (2014) 7:1395-404. doi: 10.1038/mi.2014.29

9. Johnston LK, Chien KB, Bryce PJ. The immunology of food allergy. J Immunol. (2014) 192:2529-34. doi: 10.4049/jimmunol.1303026

10. Hayen SM, Kostadinova AI, Garssen J, Otten HG, Willemsen LE. Novel immunotherapy approaches to food allergy. Curr Opin Allergy Clin Immunol. (2014) 14:549-56. doi: 10.1097/ACI.0000000000000109

11. Prince BT, Mandel MJ, Nadeau K, Singh AM. Gut microbiome and the development of food allergy and allergic disease. Pediatr Clin North Am. (2015) 62:1479-92. doi: 10.1016/j.pcl.2015.07.007

12. Aitoro R, Paparo L, Amoroso A, Di Costanzo M, Cosenza L, Granata V, et al. Gut microbiota as a target for preventive and therapeutic intervention against food allergy. Nutrients. (2017) 9:E672. doi: 10.3390/nu9070672

13. Grimshaw KE, Maskell J, Oliver EM, Morris RC, Foote KD, Mills EN, et al. Diet and food allergy development during infancy: birth cohort study findings using prospective food diary data. J Allergy Clin Immunol. (2014) 133:511-9. doi: 10.1016/j.jaci.2013.05.035

14. Trikha A, Baillargeon JG, Kuo YF, Tan A, Pierson K, Sharma G, et al. Development of food allergies in patients with gastroesophageal reflux disease treated with gastric acid suppressive medications. Pediatr Allergy Immunol. (2013) 24:582-8. doi: 10.1111/pai.12103

15. Statovci D, Aguilera M, MacSharry J, Melgar S. The impact of western diet and nutrients on the microbiota and immune response at mucosal interfaces. Front Immunol. (2017) 8:838. doi: 10.3389/fimmu.2017.00838

16. Shek LP, Chong MF, Lim JY, Soh SE, Chong YS. Role of dietary long-chain polyunsaturated fatty acids in infant allergies and respiratory diseases. Clin Dev Immunol. (2012) 2012:730568. doi: 10.1155/2012/730568

17. Koletzko B, Boey CC, Campoy C, Carlson SE, Chang N, Guillermo-Tuazon MA, et al. Current information and Asian perspectives on long-chain polyunsaturated fatty acids in pregnancy, lactation, and infancy: systematic review and practice recommendations from an early nutrition academy workshop. Ann Nutr Metab. (2014) 65:49-80. doi: 10.1159/000365767

18. Calder PC. Functional roles of fatty acids and their effects on human health. J Parenter Enteral Nutr. (2015) 39(Suppl. 1):18S-32. doi: 10.1177/0148607115595980

19. Calder PC, Yaqoob P, Harvey DJ, Watts A, Newsholme EA. Incorporation of fatty acids by concanavalin A-stimulated lymphocytes and the effect on fatty acid composition and membrane fluidity. Biochem J. (1994) 300(Pt 2):509-18. doi: 10.1042/bj3000509

20. Adolph S, Fuhrmann H, Schumann J. Unsaturated fatty acids promote the phagocytosis of $P$. aeruginosa and $R$. equi by RAW264.7 macrophages. Curr Microbiol. (2012) 65:649-55. doi: 10.1007/s00284-012-0207-3

21. Ambrozova G, Pekarova M, Lojek A. Effect of polyunsaturated fatty acids on the reactive oxygen and nitrogen species production by raw 264.7 macrophages. Eur J Nutr. (2010) 49:133-9. doi: 10.1007/s00394-0090057-3

22. Carlsson JA, Wold AE, Sandberg AS, Ostman SM. The polyunsaturated fatty acids arachidonic acid and docosahexaenoic acid induce mouse dendritic cells maturation but reduce T-cell responses in vitro. PLoS ONE. (2015) 10:e0143741. doi: 10.1371/journal.pone.0143741

23. Fuhrmann H, Miles EA, West AL, Calder PC. Membrane fatty acids, oxidative burst and phagocytosis after enrichment of P388D1 monocyte/macrophages with essential 18-carbon fatty acids. Ann Nutr Metab. (2007) 51:155-62. doi: $10.1159 / 000103276$

24. Weatherill AR, Lee JY, Zhao L, Lemay DG, Youn HS, Hwang DH. Saturated and polyunsaturated fatty acids reciprocally modulate dendritic cell functions mediated through TLR4. J Immunol. (2005) 174:5390-7. doi: 10.4049/jimmunol.174.9.5390

25. Wang H, Hao Q, Li QR, Yan XW, Ye S, Li YS, et al. Omega-3 polyunsaturated fatty acids affect lipopolysaccharide-induced maturation of dendritic cells through mitogen-activated protein kinases p38. Nutrition. (2007) 23:474-82. doi: 10.1016/j.nut.2007.04.002

26. Brix S, Lund P, Kjaer TM, Straarup EM, Hellgren LI, Frokiaer H. CD4(+) T-cell activation is differentially modulated by bacteria-primed dendritic cells, but is generally down-regulated by n-3 polyunsaturated fatty acids. Immunology. (2010) 129:338-50. doi: 10.1111/j.1365-2567.2009.03163.x

27. Hou TY, Barhoumi R, Fan YY, Rivera GM, Hannoush RN, McMurray DN, et al. n-3 polyunsaturated fatty acids suppress CD4(+) $\mathrm{T}$ cell proliferation by altering phosphatidylinositol-(4,5)-bisphosphate [PI $(4,5) \mathrm{P} 2]$ organization. Biochim Biophys Acta. (2016) 1858:85-96. doi: 10.1016/j.bbamem.2015. 10.009

28. Zurier RB, Rossetti RG, Seiler CM, Laposata M. Human peripheral blood $\mathrm{T}$ lymphocyte proliferation after activation of the $\mathrm{T}$ cell receptor: effects of unsaturated fatty acids. Prostaglandins Leukot Essent Fatty Acids. (1999) 60:371-5. doi: 10.1016/S0952-3278(99)80015-5

29. Sierra S, Lara-Villoslada F, Comalada M, Olivares M, Xaus J. Dietary fish oil n-3 fatty acids increase regulatory cytokine production and exert antiinflammatory effects in two murine models of inflammation. Lipids. (2006) 41:1115-25. doi: 10.1007/s11745-006-5061-2

30. Endo J, Arita M. Cardioprotective mechanism of omega-3 polyunsaturated fatty acids. J Cardiol. (2016) 67:22-7. doi: 10.1016/j.jjcc.2015.08.002

31. van den Elsen LW, Bol-Schoenmakers M, van Esch BC, Hofman GA, van de Heijning BJ, Pieters RH, et al. DHA-rich tuna oil effectively suppresses allergic symptoms in mice allergic to whey or peanut. J Nutr. (2014) 144:1970-6. doi: $10.3945 /$ jn. 114.198515

32. van den Elsen LW, Meulenbroek LA, van Esch BC, Hofman GA, Boon L, Garssen J, et al. CD25+ regulatory T cells transfer n-3 long chain polyunsaturated fatty acids-induced tolerance in mice allergic to cow's milk protein. Allergy. (2013) 68:1562-70. doi: 10.1111/all.12300

33. van den Elsen LW, van Esch BC, Dingjan GM, Hofman GA, Garssen J, Willemsen LE. Increased intake of vegetable oil rich in n-6 PUFA enhances allergic symptoms and prevents oral tolerance induction in wheyallergic mice. Br J Nutr. (2015) 114:577-85. doi: 10.1017/S0007114515 002007

34. Kuwamori M, Wada M, Takita T, Tadokoro T, Maekawa A, Innami S. Effect of dietary n-3/n-6 fatty acid ratio on the total count, fatty acid composition, and histamine and leukotriene concentrations of mast cells in tunica mucosa bronchiorum of type I allergic guinea pig. Biosci Biotechnol Biochem. (1997) 61:763-7. doi: 10.1271/bbb.61.763

35. Ishihara K, Murata M, Kaneniwa M, Saito H, Shinohara K, Maeda-Yamamoto M. Inhibition of icosanoid production in MC/9 mouse mast cells by $n-3$ polyunsaturated fatty acids isolated from edible marine algae. Biosci Biotechnol Biochem. (1998) 62:1412-5. doi: 10.1271/bbb.62.1412

36. Nakano N, Nakao A, Uchida T, Shirasaka N, Yoshizumi H, Okumura $\mathrm{K}$, et al. Effects of arachidonic acid analogs on FcepsilonRI-mediated activation of mast cells. Biochim Biophys Acta. (2005) 1738:19-28. doi: 10.1016/j.bbalip.2005.11.005

37. van den Elsen LW, Nusse Y, Balvers M, Redegeld FA, Knol EF, Garssen J, et al. n-3 Long-chain PUFA reduce allergy-related mediator release by human mast cells in vitro via inhibition of reactive oxygen species. Br J Nutr. (2013) 109:1821-31. doi: 10.1017/S0007114512003959

38. Nakamura T, Maeda S, Horiguchi K, Maehara T, Aritake K, Choi BI, et al. PGD2 deficiency exacerbates food antigen-induced mast cell hyperplasia. Nat Commun. (2015) 6:7514. doi: 10.1038/ncomms8514

39. Laitinen K, Hoppu U, Hamalainen M, Linderborg K, Moilanen E, Isolauri E. Breast milk fatty acids may link innate and adaptive immune regulation: analysis of soluble CD14, prostaglandin E2, and fatty acids. Pediatr Res. (2006) 59:723-7. doi: 10.1203/01.pdr.0000203158.31452.9e

40. Furuhjelm C, Warstedt K, Larsson J, Fredriksson M, Bottcher MF, FalthMagnusson K, et al. Fish oil supplementation in pregnancy and lactation may decrease the risk of infant allergy. Acta Paediatr. (2009) 98:1461-7. doi: 10.1111/j.1651-2227.2009.01355.x

41. Dunstan JA, Mori TA, Barden A, Beilin LJ, Taylor AL, Holt PG, et al. Maternal fish oil supplementation in pregnancy reduces interleukin-13 levels in cord blood of infants at high risk of atopy. Clin Exp Allergy. (2003) 33:442-8. doi: 10.1046/j.1365-2222.2003.01590.x

42. Foiles AM, Kerling EH, Wick JA, Scalabrin DM, Colombo J, Carlson SE. Formula with long-chain polyunsaturated fatty acids reduces incidence 
of allergy in early childhood. Pediatr Allergy Immunol. (2016) 27:156-61. doi: 10.1111/pai.12515

43. Aldamiz-Echevarria L, Bilbao A, Andrade F, Elorz J, Prieto JA, RodriguezSoriano J. Fatty acid deficiency profile in children with food allergy managed with elimination diets. Acta Paediatr. (2008) 97:1572-6. doi: 10.1111/j.1651-2227.2008.00963.x

44. Yu G, Bjorksten B. Polyunsaturated fatty acids in school children in relation to allergy and serum IgE levels. Pediatr Allergy Immunol. (1998) 9:133-8. doi: 10.1111/j.1399-3038.1998.tb00359.x

45. Palmer DJ, Sullivan T, Gold MS, Prescott SL, Heddle R, Gibson RA, et al. Randomized controlled trial of fish oil supplementation in pregnancy on childhood allergies. Allergy. (2013) 68:1370-6. doi: 10.1111/all.12233

46. D'Vaz N, Meldrum SJ, Dunstan JA, Martino D, McCarthy S, Metcalfe J, et al. Postnatal fish oil supplementation in high-risk infants to prevent allergy: randomized controlled trial. Pediatrics. (2012) 130:674-82. doi: 10.1542/peds.2011-3104

47. Almqvist C, Garden F, Xuan W, Mihrshahi S, Leeder SR, Oddy W, et al. Omega-3 and omega-6 fatty acid exposure from early life does not affect atopy and asthma at age 5 years. J Allergy Clin Immunol. (2007) 119:1438-44. doi: 10.1016/j.jaci.2007.01.046

48. Furuhjelm C, Warstedt K, Fageras M, Falth-Magnusson K, Larsson J, Fredriksson $\mathrm{M}$, et al. Allergic disease in infants up to 2 years of age in relation to plasma omega-3 fatty acids and maternal fish oil supplementation in pregnancy and lactation. Pediatr Allergy Immunol. (2011) 22:505-14. doi: $10.1111 /$ j.1399-3038.2010.01096.x

49. Gunaratne AW, Makrides M, Collins CT. Maternal prenatal and/or postnatal n-3 long chain polyunsaturated fatty acids (LCPUFA) supplementation for preventing allergies in early childhood. Cochrane Database Syst Rev. (2015) 7:CD010085. doi: 10.1002/14651858.CD010085.pub2

50. Lee HS, Barraza-Villarreal A, Hernandez-Vargas H, Sly PD, Biessy C, Ramakrishnan U, et al. Modulation of DNA methylation states and infant immune system by dietary supplementation with omega-3 PUFA during pregnancy in an intervention study. Am J Clin Nutr. (2013) 98:480-7. doi: 10.3945/ajcn.112.052241

51. Dunstan JA, Mori TA, Barden A, Beilin LJ, Taylor AL, Holt PG, et al. Fish oil supplementation in pregnancy modifies neonatal allergen-specific immune responses and clinical outcomes in infants at high risk of atopy: a randomized, controlled trial. J Allergy Clin Immunol. (2003) 112:1178-84. doi: 10.1016/j.jaci.2003.09.009

52. Noakes PS, Vlachava M, Kremmyda LS, Diaper ND, Miles EA, ErlewynLajeunesse $\mathrm{M}$, et al. Increased intake of oily fish in pregnancy: effects on neonatal immune responses and on clinical outcomes in infants at $6 \mathrm{mo}$. Am J Clin Nutr. (2012) 95:395-404. doi: 10.3945/ajcn.111.022954

53. Olsen SF, Sorensen JD, Secher NJ, Hedegaard M, Henriksen TB, Hansen HS, et al. Randomised controlled trial of effect of fish-oil supplementation on pregnancy duration. Lancet. (1992) 339:1003-7. doi: 10.1016/0140-6736(92)90533-9

54. Lauritzen L, Kjaer TM, Fruekilde MB, Michaelsen KF, Frokiaer H. Fish oil supplementation of lactating mothers affects cytokine production in 2 1/2-year-old children. Lipids. (2005) 40:669-76. doi: 10.1007/s11745-0051429-6

55. Manley BJ, Makrides M, Collins CT, McPhee AJ, Gibson RA, Ryan P, et al. High-dose docosahexaenoic acid supplementation of preterm infants: respiratory and allergy outcomes. Pediatrics. (2011) 128:e71-7. doi: 10.1542/peds.2010-2405

56. Willemsen LEM. Dietary $\mathrm{n}-3$ long chain polyunsaturated fatty acids in allergy prevention and asthma treatment. Eur J Pharmacol. (2016) 785:174-86. doi: 10.1016/j.ejphar.2016.03.062

57. Raederstorff D, Wyss A, Calder PC, Weber P, Eggersdorfer M. Vitamin E function and requirements in relation to PUFA. Br J Nutr. (2015) 114:1113-22. doi: $10.1017 /$ S000711451500272X

58. Singh U, Devaraj S, Jialal I. Vitamin E, oxidative stress, and inflammation. Annu Rev Nutr. (2005) 25:151-74. doi: 10.1146/annurev.nutr. 24.012003.132446

59. Shaikh SR, Wassall SR, Brown DA, Kosaraju R. N-3 polyunsaturated fatty acids, lipid microclusters, and vitamin E. Curr Top Membr. (2015) 75:209-31. doi: 10.1016/bs.ctm.2015.03.003
60. Lee OH, Seo MJ, Choi HS, Lee BY. Pycnogenol(R) inhibits lipid accumulation in 3T3-L1 adipocytes with the modulation of reactive oxygen species (ROS) production associated with antioxidant enzyme responses. Phytother Res. (2012) 26:403-11. doi: 10.1002/ptr.3568

61. Choi IS, Choi EY, Jin JY, Park HR, Choi JI, Kim SJ. Kaempferol inhibits P. intermedia lipopolysaccharide-induced production of nitric oxide through translational regulation in murine macrophages: critical role of heme oxygenase-1-mediated ROS reduction. J Periodontol. (2013) 84:545-55. doi: $10.1902 /$ jop.2012.120180

62. Zhang M, Swarts SG, Yin L, Liu C, Tian Y, Cao Y, et al. Antioxidant properties of quercetin. Adv Exp Med Biol. (2011) 701:283-9. doi: 10.1007/978-1-4419-7756-4_38

63. Tanaka T, Iuchi A, Harada $\mathrm{H}$, Hashimoto S. Potential beneficial effects of wine flavonoids on allergic diseases. Diseases. (2019) 7:8. doi: $10.3390 /$ diseases 7010008

64. Kumar S, Pandey AK. Chemistry and biological activities of flavonoids: an overview. Sci World J. (2013) 2013:162750. doi: 10.1155/2013/162750

65. Hussain T, Tan B, Yin Y, Blachier F, Tossou MC, Rahu N. Oxidative stress and inflammation: what polyphenols can do for us? Oxid Med Cell Longev. (2016) 2016:7432797. doi: 10.1155/2016/7432797

66. Belikov AV, Schraven B, Simeoni L. T cells and reactive oxygen species. $J$ Biomed Sci. (2015) 22:85. doi: 10.1186/s12929-015-0194-3

67. Andrew R, Izzo AA. Principles of pharmacological research of nutraceuticals. Br J Pharmacol. (2017) 174:1177-94. doi: 10.1111/bph.13779

68. Kosinova P, Berka K, Wykes M, Otyepka M, Trouillas P. Positioning of antioxidant quercetin and its metabolites in lipid bilayer membranes: implication for their lipid-peroxidation inhibition. J Phys Chem B. (2012) 116:1309-18. doi: 10.1021/jp208731g

69. Marunaka Y, Marunaka R, Sun H, Yamamoto T, Kanamura N, Inui T, et al. Actions of quercetin, a polyphenol, on blood pressure. Molecules. (2017) 22:E209. doi: 10.3390/molecules22020209

70. Takasugi M, Muta E, Yamada K, Arai H. A new method to evaluate anti-allergic effect of food component by measuring leukotriene B4 from a mouse mast cell line. Cytotechnology. (2018) 70:177-84. doi: 10.1007/s10616-017-0129-9

71. Park HH, Lee S, Son HY, Park SB, Kim MS, Choi EJ, et al. Flavonoids inhibit histamine release and expression of proinflammatory cytokines in mast cells. Arch Pharm Res. (2008) 31:1303-11. doi: 10.1007/s12272-001-2110-5

72. Lee EJ, Ji GE, Sung MK. Quercetin and kaempferol suppress immunoglobulin E-mediated allergic inflammation in RBL-2H3 and Caco-2 cells. Inflamm Res. (2010) 59:847-54. doi: 10.1007/s00011-010-0196-2

73. Singh A, Holvoet S, Mercenier A. Dietary polyphenols in the prevention and treatment of allergic diseases. Clin Exp Allergy. (2011) 41:1346-59. doi: $10.1111 / j .1365-2222.2011 .03773 . x$

74. Caglayan Sozmen S, Karaman M, Cilaker Micili S, Isik S, Bagriyanik A, Arikan Ayyildiz Z, et al. Effects of quercetin treatment on epithelium-derived cytokines and epithelial cell apoptosis in allergic airway inflammation mice model. Iran J Allergy Asthma Immunol. (2016) 15:487-97.

75. Sun CQ, Johnson KD, Wong H, Foo LY. Biotransformation of flavonoid conjugates with fatty acids and evaluations of their functionalities. Front Pharmacol. (2017) 8:759. doi: 10.3389/fphar.2017.00759

76. Tsiailanis A, Tsoumani M, Stylos EK, Chatziathanasiadou MV, Kellici TF, Mavromoustakos T, et al. Designing natural product hybrids bearing triple antiplatelet profile and evaluating their human plasma stability. Methods Mol Biol. (2018) 1824:371-85. doi: 10.1007/978-1-4939-8630-9_22

77. Cialdella-Kam L, Nieman DC, Knab AM, Shanely RA, Meaney MP, Jin $F$, et al. A mixed flavonoid-fish oil supplement induces immuneenhancing and anti-inflammatory transcriptomic changes in adult obese and overweight women-a randomized controlled trial. Nutrients. (2016) 8:E277. doi: $10.3390 /$ nu 8050277

78. Massaro M, Scoditti E, Carluccio MA, De Caterina R. Nutraceuticals and prevention of atherosclerosis: focus on omega-3 polyunsaturated fatty acids and Mediterranean diet polyphenols. Cardiovasc Ther. (2010) 28:e13-9. doi: 10.1111/j.1755-5922.2010.00211.x

79. Chatzi L, Kogevinas M. Prenatal and childhood Mediterranean diet and the development of asthma and allergies in children. Public Health Nutr. (2009) 12:1629-34. doi: 10.1017/S1368980009990474 
80. Chatzi L, Apostolaki G, Bibakis I, Skypala I, Bibaki-Liakou V, Tzanakis N, et al. Protective effect of fruits, vegetables and the Mediterranean diet on asthma and allergies among children in Crete. Thorax. (2007) 62:677-83. doi: 10.1136/thx.2006. 069419

81. de Batlle J, Garcia-Aymerich J, Barraza-Villarreal A, Anto JM, Romieu I. Mediterranean diet is associated with reduced asthma and rhinitis in Mexican children. Allergy. (2008) 63:1310-6. doi: 10.1111/j.1398-9995.2008. 01722.x

82. Abril-Gil M, Massot-Cladera M, Perez-Cano FJ, Castellote C, Franch A, Castell M. A diet enriched with cocoa prevents IgE synthesis in a rat allergy model. Pharmacol Res. (2012) 65:603-8. doi: 10.1016/j.phrs.2012. 02.001

83. Abril-Gil M, Perez-Cano FJ, Franch A, Castell M. Effect of a cocoa-enriched diet on immune response and anaphylaxis in a food allergy model in Brown Norway rats. J Nutr Biochem. (2016) 27:317-26. doi: 10.1016/j.jnutbio.2015. 09.022

84. Galarraga B, Ho M, Youssef HM, Hill A, McMahon H, Hall C, et al. Cod liver oil (n-3 fatty acids) as an non-steroidal anti-inflammatorydrug sparing agent in rheumatoid arthritis. Rheumatology. (2008) 47:665-9. doi: 10.1093/rheumatology/ken024

85. Mai XM, Langhammer A, Chen Y, Camargo CA Jr. Cod liver oil intake and incidence of asthma in Norwegian adults-the HUNT study. Thorax. (2013) 68:25-30. doi: 10.1136/thoraxjnl-2012-202061

Conflict of Interest Statement: JG is employed by Nutricia Research BV.

The remaining authors declare that the research was conducted in the absence of any commercial or financial relationships that could be construed as a potential conflict of interest.

Copyright (c) 2019 Hoppenbrouwers, Cvejić Hogervorst, Garssen, Wichers and Willemsen. This is an open-access article distributed under the terms of the Creative Commons Attribution License (CC BY). The use, distribution or reproduction in other forums is permitted, provided the original author(s) and the copyright owner(s) are credited and that the original publication in this journal is cited, in accordance with accepted academic practice. No use, distribution or reproduction is permitted which does not comply with these terms. 